NBER WORKING PAPER SERIES

\title{
MEAN REVERSION IN EQUILIBRIUM ASSET PRICES
}

\author{
Stephen G. Cecchetti \\ Pok-sang Lam \\ Nelson C. Mark
}

Working Paper No. 2762

\author{
NATIONAL BUREAU OF ECONOMIC RESEARCH \\ 1050 Massachusetts Avenue \\ Cambridge, MA 02138 \\ November 1988
}

We thank Ben Bernanke, Paul Evans, David Backus, Alan Gregory, Hu McCulloch, Robert Shiller, and Larry Summers for useful comments on an earlier draft. This research is part of NBER's research program in Financial Markets and Monetary Economics. Any opinions expressed are those of the authors not those of the National Bureau of Economic Research. 
NBER Working Paper \#2762

November 1988

MEAN REVERSION IN EQUILIBRIUM ASSET PRICES

\section{ABSTRACT}

Recent empirical studies have found that stock returns contain substantial negative serial correlation at long horizons. We examine this finding with a series of Monte Carlo simulations in order to demonstrate that it is consistent with an equilibrium model of asset pricing. When investors display only a moderate degree of risk aversion, commonly used measures of mean reversion in stock prices calculated from actual returns data nearly always lie within a 60 percent confidence interval of the median of the Monte Carlo distributions. From this evidence, we conclude that the degree of serial correlation in the data could plausibly have been generated by our model.

\footnotetext{
Stephen G. Cecchetti

Department of Economics Ohio State University

Columbus, Ohio 43210

Nelson C. Mark

Department of Economics

Ohio State University

Columbus, Ohio 43210
}

Pok-sang Lam

Department of Economics

Stanford University

Stanford, CA 94305 


\section{Introduction}

Recent research into the behavior of the stock market reports evidence that returns are negatively serially correlated. Poterba and Summers (1987) find that variance ratio tests reject the hypothesis that stock prices follow a random walk, and Fama and French (1988) show that there is significant autocorrelation in long-horizon returns. 1 It is well known [see Leroy (1973), Lucas (1978), and Michener (1982)] that serial correlation of returns does not in itself imply a violation of market efficiency. ${ }^{2}$ Nevertheless, there is a tendency to conclude that evidence of mean reversion in stock prices constitutes a rejection of equilibrium models of rational asset pricing. Fama and French suggest this interpretation as a logical possibility, while Poterba and Summers argue that the serial correlation in returns should be attributed to "price fads". In this paper we demonstrate that the empirically estimated serial correlation of stock returns is consistent with an equilibrium model of asset pricing.

The method and organization of the paper is as follows. The next section discusses the equilibrium asset pricing model that we study. Ve

1. Poterba and Sumers find negative serial correlation for stock returns over long horizons using monthly and annual data. Interestingly, Lo and Mackinlay (forthcoming) find that stock returns are positively correlated, using weekly observations.

2. Grossman and Shiller (1981) make this same point in showing that the "excess" volatility implied by variance bounds tests can be partly explained by risk aversion in a consumption beta model. More recently, Black (1988) has discussed the relation between mean reversion and consumption smoothing. 
begin with Lucas' (1978) model of an exchange economy and adopt parametric representations for preferences and the stochastic process governing the exogenous forcing variable (i.e., the endowment stream) which admit a closed form solution to the asset pricing problem. The period utility function we work with is the constant relative risk aversion function. For preferences of this sort, the coefficient of relative risk aversion is also the inverse of the elasticity of intertemporal substitution in consumption so that it is difficult to seperate agents' tolerance for risk from their desire to have smooth consumption. However, in a setting where agents confront an intertemporal consumption/investment problem it makes more sense to interpret the concavity of the utility function in terms of the consumption smoothing motive, and that is the interpretation we make. The exogenous forcing variable is assumed to obey Hamilton's (1988) Markov trend in logarithms model. This model conveniently incorporates important business cycle properties which are characteristic of many economic time series. In particular, Hamilton's representation is able to capture stochastic switching between positive and negative growth regimes of the time series and its asymmetric growth over the course of the cycle [Neftci (1984)]. Next, the parameters of the Markov trend in logarithms nodel are estimated by maximum likelihood using annual observations on the U.S. economy. This is done so that we can calibrate the asset pricing model by setting the parameters of the exogenous forcing process equal to these maximun likelihood estimates. Unfortunately, the theory provides little guidance regarding the appropriate time series on which to calibrate the model because in the Lucas model, equilibrium consumption equals output which also equals dividends. Empirically, none of these time series appear to be more appropriate than the others a priori, so ve calibrate the model 
seperately to each of the three series. It turns out that our results are robust to variations in the time series on which we calibrate the model. The maximum likelihood estimates of the Markov trend in logarithms model for dividends, consumption, and GNP are reported in section 3 .

In section 4, we study the measures of mean reversion which have appeared in the literature. These are the variance ratio statistics used by Poterba and Summers and the regression coefficients calculated by Fama and French. ${ }^{3}$ First, we caluclate these statistics from historical data on the Standard and Poors 500 returns. Next, a Monte Carlo distribution of these statistics is generated under the assunption that our equilibriun model of asset pricing is true. Inferences regarding the equilibrium model are then drawn using classical hypothesis testing procedures and the Monte Carlo distribution as the null. We are principally interested in two hypotheses. The first is the random walk model of stock prices, which is an implication of the Lucas model when agents have linear utility. The second hypothesis is that observed asset prices are determined in equilibrium but agents attempt to smooth their consumption. In this setting, asset returns can be negatively serially correlated even though they rationally reflect market fundamentals.

To summarize our results, we find, for all return horizons longer than one year, that the variance ratio statistics and regression coefficients calculated from the actual Standard and Poors returns lie near

3. We might also have examined variance bounds tests. But as Campbell and Shiller (1988) point out, there is an equivalence between variance ratio tests of the type in Poterba and Summers and variance bounds tests pioneered by Shiller (1981). 
the 60 percent confidence band of the median of the Monte Carlo distribution generated under the linear utility (random walk) model. When investors display only a moderate desire to smooth their consumption, these same statistics calculated from the data lie at or near the median of the Monte Carlo distribution. When ve test the null hypothesis against a diffuse alternative, we cannot reject the randon walk model at the standard 5 percent significance level. However, the marginal significance levels of the test are much smaller when the null distribution is generated assuming the utility function is concave. We conclude that much of the serial correlation in actual stock returns can be attributed to small sample bias but a full explanation requires concavity of the utility function.

\section{The Bquilibrium Model.}

\subsection{A Case of the Lucas Model.}

Consider the economy studied by Lucas (1978) in which there are a large number of infinitely lived and identical agents and a fixed number of assets which exogenously produce units of the same nonstoreable consumption good. Let there be $\mathrm{K}$ agents and $\mathrm{N}$ productive units. Each assec has a single perfectly divisible claim outstanding on $i t$, and these claims are traded in a competitive equity market. The first-order necessary conditions for a typical agent's optimization problem are,

$$
P_{j, t} U^{\prime}\left(C_{t}\right)=\beta E_{t} U^{\prime}\left(C_{t+1}\right)\left[P_{j, t+1}+D_{j, t+1}\right], \quad j=1,2, \ldots, N
$$

where $P_{j} \quad=$ The real price of asset $j$ in terms of the consumption good. 


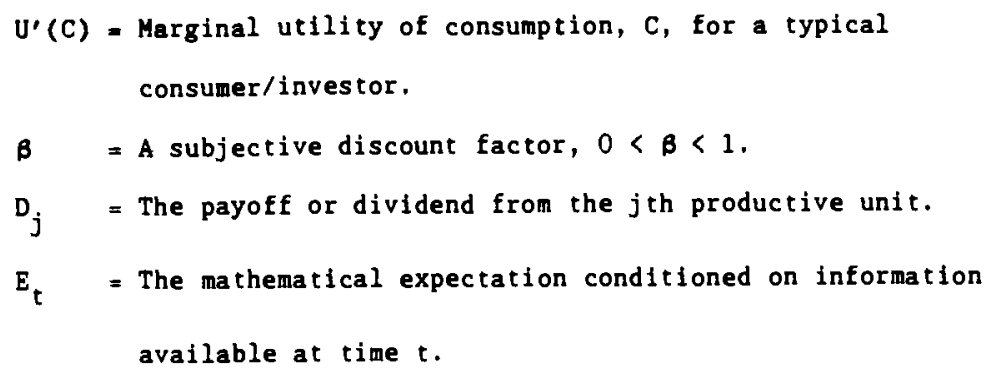

In equilibrium, per capita ownership of asset $j$ is $1 / K$. It follows that equilibrium per capita consumption, $C$, is the per capita claim to the total endowment in that period, $(1 / K) \varepsilon_{j=1}^{N} D_{j}$. Now, make this substitution in equation (1) and sum over $f$ to obtain an equilibrium condition involving economy wide or market prices and quantities on a per capita basis. That is,

$$
P_{t} U^{\prime}\left(D_{t}\right)=B E_{t} U^{\prime}\left(D_{t+1}\right)\left[P_{t+1}+D_{t+1}\right]
$$

where $P_{t} \equiv(1 / K) \sum P_{j, t}$ is the share of the market's value owned by a typical agent and $D_{t}=(1 / K) \sum D_{j, t^{*}}$. Since each productive unit has only a single share outstanding, and the number of productive units are fixed, these are the theoretical value weighted market indices adjusted for population.

Let preferences be given by constant relative risk aversion utility:

$$
U(C)=(1+\gamma)^{-1} C^{(1+\gamma)} \text {, }
$$


where $-\infty<\gamma \leq 0$ is the coefficient of relative risk aversion. Now (2) simplifies to a stochastic difference equation which is linear in $\mathrm{PD}^{\Upsilon}$. That is,

$$
P_{t} D_{t}^{Y}=\beta E_{t} P_{t+1} D_{t+1}^{Y}+\beta E_{t} D_{t+1}^{(1+\gamma)}
$$

Iterating (3) forward, the current market value, ${ }_{t}$, can be expressed as a nonlinear function of current and expected future payoffs,

$$
P_{t}=D_{t}^{-\gamma} \sum_{k=1}^{\infty} \beta^{k} E_{t} D_{t+k}^{(1+\gamma)}
$$

To obtain a closed form solution, we must specify the stochastic process governing $\left(D_{t}\right)$ and this is done in the next subsection. We will refer to the exogenous forcing variable as dividends in the next two subsections. We do this because it helps to clarify the exposition, not because we restrict our attention to dividends when assessing the performance of the model. In fact, we consider alternative processes as well.

\subsection{A Nonlinear Stochastic Model for the Bxogenous Porcing Process.}

Hamilton (1987) has suggested modeling the trends in nonstationary time series as Markov processes, and has applied this approach to the study of post-World War II real GNP. One of the attractive features of this approach is its ability to account for the asymmetric behavior that many macroeconomic time series display over the business cycle. Hamilton reports 
estimates of the U.S. economy's growth state which coincide closely with NBER dating of postwar recessions, and Lam (1988) shows that the model forecasts real GNP better at short horizons than either the random walk model or autoregressions of low order. Since the observations we use are cyclical and display asymmetries characteristic of economic time series over the cycle, they are natural candidates for this specification. Let $d_{t}$ denote the logarithm of the exogenous forcing variable $D_{t}$. The Markov trend in logarithms model can be written as,

$$
d_{t}=d_{t-1}+\varepsilon_{t}+\alpha_{0}+\alpha_{1} s_{t-1}
$$

where $\left(\varepsilon_{t}\right)$ is a sequence of independent and identically distributed normal variates with zero mean and variance $\sigma^{2}$, and $\left(s_{t}\right)$ is a sequence of Markov random variables which take on values of 0 or 1 with transition probabilities,

$$
\begin{aligned}
& \operatorname{Pr}\left[s_{t}=1 \mid s_{t-1}=1\right]=p \\
& \operatorname{Pr}\left[s_{t}=0 \mid s_{t-1}=1\right]=1-p \\
& \operatorname{Pr}\left[s_{t}=0 \mid s_{t-1}=0\right]=q,
\end{aligned}
$$

and $\quad \operatorname{Pr}\left[s_{t}=1 \mid s_{t-1}=0\right]=1-q$.

The exogenous forcing process thus follows a random walk in logarithms $\left(d_{t}=d_{t-1}+\varepsilon_{t}\right)$ with stochastic drift $\left(\alpha_{0}+\alpha_{1} s_{t-1}\right)$. At this point, we make a normalization by requiring $\alpha_{0}>0$ and $\alpha_{1}<0$. We are said to be in a high 
growth (boom) state when $s=0$, and in a low growth (depression) state when $s=1$. The probability of a boom next period given that the economy currently enjoys a boom is $q$, while the probability of a depression next period given a current depression state is $p$. The probabilities of transition from boom to depression and depression to boom are then $1-q$ and 1-p respectively. The exogenous forcing variable grows at the rate $\alpha_{0}$ during a boom, and $\alpha_{0}+\alpha_{1}$ during a depression. The process $\left\{s_{t}\right\}$ can be represented as a first-order autoregression with an autocorrelation coefficient of $(p+q-1)$ which can be interpreted as a measure of persistence in the forcing process.

It is also useful to think of the process loosely within the following context. The theory relates dividends to asset prices. In actual economies, future nominal dividend payments are announced in advance so a good deal of next period's dividend growth is currently known. This is captured by the timing of the state in the Markov trend and in the next subsection, agents in the artificial economy will be assumed to observe the current state of the economy. From (5), the forecastable part of dividend growth during period $t-1$ is $\alpha_{0}+\alpha_{1} s_{t-1}$, which is revealed at $t-1$. The unforecastable part of real dividend growth, $\varepsilon_{t}$, might be thought of as a combination of unanticipated inflation and productivity shocks.

We note at this point that it is the data, and not the discretion of the investigator which will choose the regime. That is, when ve calculate the Monte Carlo distributions implied by the model, the parameters $\left(\alpha_{0}, \alpha_{1}, p, q, \sigma\right)$ of the forcing process will be set equal to maximum likelihood estimates obtained from the data. 


\subsection{Bquilibriun Asset Prices.}

Assuming that the process driving the exogenous forcing variable is given by (5) and (6), we show in the appendix that the solution to (4) is,

$$
P_{t}=\rho\left(s_{t}\right) D_{t},
$$

where $\rho\left(s_{t}\right)=\frac{\tilde{\beta} g\left(s_{t}\right)\left[1-\tilde{\beta} f\left(s_{t}\right)\right]}{1-\bar{\beta}\left[p \alpha_{1}+q\right]+\bar{\beta}^{2}(p+q-1) \tilde{a}_{1}}$,

$\tilde{\beta}=\beta \exp \left[\alpha_{0}(1+\gamma)+(1+\gamma)^{2} \sigma^{2} / 2\right]$,

$\tilde{\alpha}_{1}=\exp \left[\alpha_{1}(1+\gamma)\right]$,

$$
\begin{aligned}
& g\left(s_{t}\right)= \begin{cases}1 & s_{t}=0 \\
\bar{a}_{1} & s_{t}=1\end{cases} \\
& f\left(s_{t}\right)=\left\{\begin{array}{ll}
(p+q-1) \tilde{\alpha}_{1} & s_{t}=0 \\
p+q-1 & s_{t}=1
\end{array} .\right.
\end{aligned}
$$

A number of interesting features of the equilibrium price function emerge. First, asset prices are proportional to the forcing variable. 4

4. In the simple model studied here this implies that the price dividend ratio takes on one of two values, $\rho(0)$ or $\rho(1)$. This is a consequence of assuming that agents observe $s_{t}$. In the more realistic case in which $s_{t}$ is unobserved and must be estimated, the price dividend ratio vould be a continuous variable fluctuating between the two bounds of $\rho(0)$ and $\rho(1)$. 
Second, the factor of proportionality depends on investors' the inverse of the elasticity of intertemporal substitution and whether the economy is currently in the high growth state or low growth state according to,

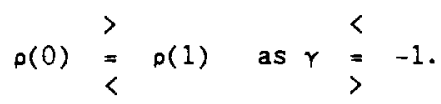

The interpretation of this is straightforward. For a given level of current dividends, suppose that the economy is known to be in a high growth state $\left(s_{t}=0\right)$. By $(6)$, this implies that the economy is likely to remain in a high growth state into the future, and hence anticipated future dividends are high. This has two effects on asset prices that work in opposite directions. First, there is what we refer to as a wealth effect in which higher expected future dividends cause agents to want to increase their asset holdings. The increased asset demand arising from the wealth effect works to raise current asset prices. Working in the opposite direction is a substitution effect arising from agents' attempts to smooth their consumption paths. When expected future dividends are high, the consumption smoothing motive leads agents to want to increase current consumption in anticipation of higher future investment income. To finance higher current consumption, agents attempt to sell off part of their asset holdings, which, in equilibrium results in falling asset prices. Log utility $(r=-1)$ is a borderline case in which the wealth effect and the substitution effect exactly cancel out. This can be seen, perhaps, more clearly from (4) in which the solution for $\gamma=-1$ is $P_{t}=(\beta /[1-\beta]) D_{t}$. In this case, the factor of proportionality relating prices to dividends is a constant. When 
the concavity of the utility function is less than it is in the log case, the weal th effect assumes greater importance, so that $\rho(0)>\rho(1)$. In the limiting case of linear utility $(\gamma=0)$, the wealth effect is all that matters, since agents have no desire to smooth consumption. Conversely, when the utility function is more concave than is implied by log utilfty, the intertemporal substitution effect dominates the wealth effect causing $\rho(1)>\rho(0)$.

From (5) and (7), equilibrium gross returns are computed as,

$$
R_{t}=\left(P_{t}+D_{t}\right) / P_{t-1}=\left\{\left[\rho\left(s_{t}\right)+1\right] / p\left(s_{t-1}\right)\right\} \exp \left[\alpha_{0}+\alpha_{1} s_{t-1}+\varepsilon_{t}\right]
$$

Notice that because the gross return depends on $\varepsilon_{t}$ it is a continuous random variable on $[0, \infty)$, and not a two point process.

\section{Maxinun Likelihood Estimates of the Markov Trend in Logarithns Process.}

This section presents estimation results for the Markov trend in logarithms model of the exogenous forcing variable. The Markov trend model is nonlinear in the sense that current values of the forcing variable cannot be expressed as a linear function of past values. Even though the state, $s$, is unobservable to the econometrician, given the normality assumption on the $\varepsilon^{\prime} s$, the parameters of the process, $\left(p, q, \alpha_{0}, \alpha_{1}, \sigma\right)$ can be estimated by maximum likelihood. The interested reader is directed to Hamilton (1987) for details on estimation or Lam (1988) who generalizes the Hamilton model. When we proceed to generate the Monte Carlo distributions from which we draw statistical inference regarding the model, the parameters of the model will 
be set to the maximum likelihood estimates to match the process driving our model to U.S. historical data.

The theory offers little guidance regarding the appropriate empirical counterpart to the exogenous forcing variable. That is because equilibrium consumption of section 2.1 equals output which also equals dividends. Consequently, we consider three time series, all in per capita terms ${ }^{5}$ : real dividends, real consumption, and real GNP.

The dividend data are annual observations from the Standard and Poors 500 index deflated by the CPI from 1871 to $1985 .{ }^{6}$ We use these data as a benchmark because they represent the longest available time series, and we believe that the characteristics of these data are representative of equity returns and dividend disbursements in general. Also, the Standard and Poors 500 index is one of the data sets used by Poterba and Sumners, so a direct comparison can be made with some of their results. We follow both Poterba and Summers and Fama and French in deflating returns by the CPI.

5. In an earlier version of this paper, the adjustment for population growth was not made. There is virtually no difference between the results with and without this adjustment.

6. This is the Standard and Poors historical data used by Summers and Poterba. Observations on returns and the CPI from 1871 to 1926 are from Vilson and Jones (1987), and from Ibbotson and Sinquefield (1982) from 1926 to 1985. Observations on nominal dividends are those used by Campbell and Shiller (1987).

7. The choice of deflator is not innocuous. As both Poterba and Summers and Fama and French state, there is little difference between using nominal returns and real returns deflated by the CPI. However, we found little evidence of mean reversion in the Standard and Poors data when returns were (Footnote continues on next page) 
The consumption data are constructed by splicing the Kendrick consumption series, published in Balke and Gordon (1986), from 1889 to 1928 to the National Income and Product Accounts data from 1929 to 1985. The real GNP data is constructed by combining observations from 1869 to 1908 from Romer (1989) with data from 1909 to 1928 from Romer (1985), and observations from 1929 to 1985 from the National Income and Product Accounts. per capita observations on each of these time-series are then obtained by dividing them by annual population estimates from the Historical Statistics of the United States and the Economic Report of the President.

The estimation results and some sumary statistics are reported in Table 1. For the most part, the parameters are accurately estimated. When the economy is in a boom this year, the estimated probability that it continues in a boom next year is $q$. As can be seen, this is .95 for dividends, .98 for GNP and .98 for consumption. The estimated rate of growth during a boom, $\alpha_{0}$, is .013, .016, and .015 for dividends, GNP, and consumption, respectively. When in a boom, the estimated probability of a transition to a negative growth state next period, 1-q, is .05 for dividends, and .02 for GNP and consumption. This implies that we might expect to observe a crash once every 20 years or so for dividends, and every 50 years for consumption and GNP. While in a depression state,

(Footnote continued from previous page)

deflated by the PPI. This is not surprising given the difference between the two measures of inflation. It is well known that the CPI tends to be very persistent, while the PPI, which behaves more like an asset price, tends to be very noisy. 
expected growth, $\alpha_{0}+\alpha_{1}$ ' is -.36 for dividends, -.16 for GNP and -.08 for consumption. At first glance, the expected rate of decline in dividends seems quite large. But, negative growth rates of this magnitude have actually occured with some degree of regularity. In fact, real dividends fell by more than 36 percent during 4 of the 116 years of our sample. ${ }^{8}$ once the economy finds itself in a depression, the probability that it will be in a depression the following year, $p$, is estimated to be .1748 for dividends, .5096 for GNP and .5279 for consumption. We note that the likelihood function is flat for variations in $p$ in estimation of the process using the dividend data. This is not surprising given the asymmetric behavior of dividends over the business cycle. That is, downturns have generally been short lived, lasting between 4 and 6 quarters. This makes $1 t$ difficult to obtain a good estimate of $p$ using annul observations. 9

We now turn to the study of equilibrium asset prices implied by this nonstationary dividend process.

\section{The Serial Correlation of Equilibriun and Actual Returns.}

In this section, returns obtained from the equilibrium model of Section 2 are used to generate Monte Carlo distributions of the variance

8. There were 9 years in the sample in which dividends fell between 10 and 20 percent, and 4 years in which they fell between 20 and 30 percent.

9. These estimates also appear reasonable in that they produce artificial sample paths (generated as described in the next section) that look remarkably like the actual time series. 
ratio statistic used by Poterba and Summers, and the regression coefficients calculated by Fama and French. These distributions are generated both for the case of linear utility and for a case in which the utility function is concave. They are then used to draw inference about the equilibrium model and the model driving the exogenous forcing variable. For each assumption about the degree of investor risk aversion, the model is calibrated to the estimated dividend, consumption, and GNP processes reported in table 1. That is, the parameters of the forcing process, $\left(p, q, \sigma, \alpha_{0}, \alpha_{1}\right)$, are set to the values in the columns of table 1 and each case is considered in turn. The subjective discount factor $\beta$ is assumed to be 0.98 throughout. The procedure is as follows: First, gtven $p$ and $q$, we generate a sequence of $116 s_{t}^{\prime}$ s according to (6). Second, given $\sigma$, we 116 independent draws from a normal distribution with zero mean and variance $\sigma^{2}$ are taken to form a sequence of $\varepsilon_{t}^{\prime} s$. Third, given $\alpha_{0}, \alpha_{1}, \beta, \gamma,\left\{s_{t}\right\}$, and $\left\{\varepsilon_{t}\right\}$, we generate a sample of 116 returns according to equation (7). For each sample of returns the variance ratio and regression coeffictent are calculated for horizons 1 through 10. This experiment is repeated 10,000 times. The tabulation of these calculations is the Monte Carlo distribution of the statistic from which we draw inference. The sample size of 116 is chosen to correspond to the 116 annual observations available in the actual Standard and Poors returns. To facilitate the exposition, we report the results in figures. 10 We calculate the median and 60 percent confidence intervals about the median

10. An appendix presenting the results in tabular form is available upon request. 
of the distribution for the statistic under investigation. A median is also calculated from 1,000 time series samples of 1160 returns each to get an idea of the "true" or large sample value of the variance ratio or regression coeficient statistics. We refer to this as the "large" sample median. In the case of linear utility, the true values are known, and this calculation gives us a loose idea of the rate of convergence of these statistics to their true values. When the utility function is concave, analytic calculation of the true values is difficult and we take this calculation to be the true large sample values. Each figure displays the large and small sample medians, the 60 percent confidence intervals about the small sample median and the point estimates calculated from actual Standard and Poors returns.

Given the Monte Carlo distributions of the variance ratio statistic and the autocorrelation coefficient on returns, we can determine the likelihood that the estimates obtained from actual data vere drawn from the Monte Carlo distribution implied by equilibrium returns.

\subsection{Variance Ratios.}

Let $R_{t}$ be the one period real rate of return, and $R_{t}^{k}$ be the simple $k$-period return. That is, $R_{t}^{k}=\varepsilon_{j=0}^{k-1} R_{t-j}$. The variance ratio for returns at the $k$ th horizon is defined as,

$$
\operatorname{VR}(k)=\frac{\operatorname{Var}\left(R_{t}^{k}\right)}{k \operatorname{Var}\left(R_{t}\right)}
$$


It is easy to show that the the variance ratio can be expressed in terms of the return's autocorrelations. That is,

$$
\operatorname{VR}(k)=1+\frac{2}{k} \sum_{j=1}^{k-1}(k-j) \rho_{j},
$$

where $o_{j}$ is the $j$ th autocorrelation on returns. When returns are serially uncorrelated, the variance ratio is equal to one for all $k$ in large

samples. 11 This is usually taken as the null hypothesis in tests of "market efficiency," corresponds to the case where stock prices follow a random walk, and is true in the equilibrium model of Section 2 only when investors have linear utility. Stock prices are said to be "mean reverting" if returns are negatively correlated and evidence of mean reversion is inferred from variance ratios which lie below unity. This is the finding of Poterba and Summers.

We consider first the case of linear utility. Figures 1-3 display the results under linear utility for models calibrated to the dividend, GNP, and consumption processes respectively. Since these returns are uncorrelated by construction, all of the deviation of the median of the variance ratio's distribution from unity is due to small sample bias. The serial correlation of returns, and hence their predictability is only apparent. This result can be viewed in the same light as the business cycle

11. In small samples, as Poterba and Summers point out, the sample autocorrelations of returns are biased so $E[V R(k)] \notin 1$ even when returns are independen $t$. 
in which recessions occur with random periodicity. Although real GNP may appear to be mean reverting, this does not imply that business cycle turning points are predictable. In the equilibrium model of asset prices, the exogenous forcing variable has a business cycle interpretation. Since equilibrium asset prices are proportional to the forcing variable, and its stochastic process implies that a boom is usually followed by a boom, the appearance of mean reversion in asset prices is produced, but this does not mean that returns are predictable. In the large sample $(T=1160)$, most of the bias has dissappeared. In Figure 1, it is seen that the variance ratios calculated from the Standard and Poors data fall within the 60 percent confidence interval of the Monte Carlo distribution except at the 7 , 8 , and 9 year horizons when the model is calibrated to the dividend process. 12 However, these outliers are still within the traditional 95 percent confidence interval. The evidence is more favorable to the model when the forcing process is matched to consumption and GNP. Figures 2 and 3 display variance ratios calculated from the actual data which lie uniformly within the 60 percent confidence interval of the median of the Monte Carlo distribution.

When agents' utility function is concave, the results are even more favorable to the model. Figure 4 reports the results of the above calculations assuming concave utility with $\gamma=-1.4$ and the forcing process matched to the dividends. Now the median of both the small and large sample

12. These estimates of the variance ratios are smaller than those reported by Poterba and Summers because they make a bias correction assuming a null hypothesis of a homoskedastic random walk for asset prices. The bias correction is irrelevant for our purposes. 
distributions of the variance ratio statistics are well below 1.0 at every horizon. The median of the small sample $(T=116)$ distribution is actually below the variance ratios calculated from the annual returns on the $S \& P$ 500 , which implies that the equilibrium model with $Y=-1.4$ generates more negative serial correlation in returns than is found in the actual data. 13 We find that the general pattern of the variance ratios calculated from the data is replicated rather well by the large sample median of the Monte Carlo distribution at all but the first horizon. The discrepancy at the first horizon occurs because there is almost no first order serial correlation in the annual returns data, while the equilibrium model produces some negative first order serial correlation.

Figures 5 and 6 display the results when the forcing process is calibrated to the GNP process where the coefficient of relative risk aversion is -1.6 , and the consumption process where the coefficient of relative risk aversion is -1.7 respectively. Here, the variance ratios calculated from the $S \& P$ returns lie close to the median of the distribution, and are uniformly within the 60 percent confidence interval about the median. ${ }^{14}$ Ve conclude that the model cannot be rejected at less than the 60 percent level whether the consumption smoothing motive is present or not.

13. When $y=-2$, the model yields much more mean reversion than is in the data. The entire $60 \%$ confidence band lies below the sample values.

14. The above calculations were also performed for $Y=-4.0$. As investors become more risk averse, the negative serial correlation in returns increases at a decreasing rate, and so the median of the Monte Carlo distribution of the variance ratio statistics moves further below 1.0 . 


\subsection{Regression Coefficients on Returns of Varying Horizons.}

Consider estimating the first-order serial correlation coefficient on $\tau$-period returns by running the following regression:

$$
R_{t, t+\tau}=a_{\tau}+b_{\tau} R_{t-\tau, t}+u_{t, t+\tau}, \tau=1,2, \ldots, 10
$$

where $R_{t, t+\tau}$ is the continuously compounded real stock return from to $t+\tau$. It is easy to show that the relation between the autocorrelations of oneperiod returns and the autocorrelation of the $\tau$-period return is,

$$
b_{\tau}=\frac{\rho_{1}+2 \rho_{2}+\cdots+\tau \rho_{\tau}+(\tau-1) \rho_{\tau+1}+\cdots+2 \rho_{2 \tau-2}+\rho_{2 \tau-1}}{\tau+2(\tau-1) \rho_{1}+2(\tau-2) \rho_{2}+\cdots+2 \rho_{\tau-1}}
$$

Using monthly returns on the CRSP index, Fama and French find that the slope coefficient $b_{\tau}$ is negative for $\tau$ greater than one year. From this they infer that stock prices are mean reverting. We examine their result by computing the empirical distribution of these regression coefficients impiied by the model in Section 2.

We begin with the linear utility $(\gamma=0)$ case. Figures $7-9$ display For the model calibrated to dividends, GNP, and consumption respectively, the median and 60 percent confidence intervals of the Monte Carlo distribution of the regression coefficient $b_{\tau}$; the large sample $(T=1160)$ median, the estimates obtained from the Standard and Poors returns, and the Monte Carlo distribution function evaluated at these estimated values. Again, the deviation of the median of the small sample ( $T=116)$ distribution 
from zero is due to small sample bias. This bias increases as $\tau$ gets larger, because the effective sample size, as measured by the number of independent pieces of information (non-overlapping observations), decreases vith $\tau$. For example, at the 10 year horizon, there are only 10 nonoverlapping observations available in the Standard and Poors data, and 6 non-overlapping observations available in the CRSP returns! The median of the large sample distribution $(T=1160)$ on the other hand, is reasonably close to the true value of zero. The regression coefficients calculated from the Standard and Poors data generally lie below the median of the small sample Monte Carlo distribution. For the dividend model, they are within the 60 percent confidence interval about the median except for the estimate obtained using 2 year returns. For the consumption and GNP models, the estimates lie uniformly within the 60 percent confidence intervals.

Figures 10-12 display the details of the Monte Carlo distributions of the regression coefficients obtained from the equilibrium returns when $r$ is -1.4 in the dividend model, -1.6 in the GNP model and -1.7 in the consumption model. Here, it is the regression coefficient for one year returns which falls outside the 60 percent confidence interval of the small sample median of the dividend model but lie uniformly within this interval for the consumption and GNP models. The distance between the small sample medians and the actual estimates tend to be smaller here than when agents have linear utility.

\subsection{Mean Reversion, Saall Sample Bias, and Consumption Smoothing -}

The results of the previous two subsections show that small sample bias and concavity of the utility function work to generate returns which appear mean reverting. Table 2 isolates the contribution of each of these 
effects. For each of the forcing processes on which the model is calibrated, we report the deviation of the small sample median from the theoretical value when agents have linear utility (column 1), and the difference of the median generated under concave utility from the median generated under linear utility (column 2). When the model is calibrated to the dividend process, consumption smoothing seems to be the dominant effect in the calculation of the variance ratio. In every other case, however, the small sample bias dominates at the longer horizon while consumption smoothing dominates at the short horizons.

\section{Conclusion.}

Is mean reversion in stock prices evidence of market inefficiency? Ve investigate this question by asking whether the empirically observed time series properties of stock returns can be generated by an equilibrium model of asset pricing. Monte Carlo distributions of variance ratio statistics and long horizon return regression coefficients are generated using equilibrium returns derived from the Lucas (1978) model and a nonstationary Markov process governing dividends, consumption, and GNP. We conclude that the equilibrium model cannot be rejected in the sense that the estimates of serial correlation in stock returns using actual data could reasonabiy have been drawn from our Monte Carlo distribution. This result is stronger when agents in the equilibrium model care about smoothing their consumption paths. In fact, if the coefficient of relative risk aversion is between 1.4 and 1.7, implying an intertemporal elasticity of substitution in consumption is between .58 and .71 , the median of the simulated distributions conforms very well to the actual estimates. Perhaps surprisingly, a reasonably high elasticity of intertemporal substitution has substantive effects on the 
serial correlation exhibited by simulated return series. It does not take much for the desire to smooth consumption to dominate any wealth effects produced by changes in dividends and lead to mean reversion in asset prices. Furthermore, our results are robust to a variety of assumptions regarding the properties of the exogenous forcing variable.

We make two final points regarding our results. The first concerns the time series properties of the exogenous forcing variable. We believe that this process, whether it be dividends, consumption, or GNP, is properly modeled as a nonlinear stochastic process. If we are correct, this induces the standard specification error into computations that are based on assuming that this time series is some sort of linear process. ${ }^{15}$ While this error could lead an investigator to find either too much or too little serial correlation, given the process which we estimate, it is more likely the error will lead to too little.

The second point concerns small sample bias and the implications of this bias for power in hypothesis testing. When computing statistics based on returns at five or ten year horizons, 116 annual observations is very little data. The bias is also seen to grow as the effective sample size gets smaller. The implication for testing the null against local alternatives is complementary to Summer's (1986) point that most tests of market efficiency have virtually no power against what he calls fad alternatives. Since we have shown that a properly constructed equilibrium model can generate rational asset prices which exhibit a very wide range of time series

15. The recent paper by West (1988) is an example. 
properties, it follows that, given the available data, the test of any fad model will have very little power against the rather wide class of equilibrium alternatives. More precise estimates and more powerful tests can only come through the passage of time and not by sampling the data more frequently. ${ }^{16}$ If there had been a well functioning asset market since the time of the Norman invasion (1066 A.D.) and we had all the necessary price. and dividend data, then we might begin to distinguish among some of the competing theories.

16. That is, in computing the autocorrelation of ten year returns, what is needed is more ten year time periods and not weekly or daily observations. All we can do is vait. 


\section{References}

Balke, Nathan S. and Robert J. Gordon, "Appendix B. Historical Data," In R.J. Gordon, ed., The American Business Cycle. Chicago, Ill: University of Chicago Press (for NBER), 1986.

Black, Fischer, "Mean Reversion and Consumption Smoothing," manuscript, Goldman Sachs and Co., October 1988.

Campbell, John Y. and Robert J. Shiller, "Cointegration and Tests of Present Value Models," Journal of Political Economy, Volume 95, (October 1987), $1062-1088$.

. "Stock Prices, Earnings and Expected Dividends," Journal of Finance, 63, July, 1988.

Fama, Eugene F. and Kenneth R. French, "Permanent and Temporary Components of Stock Prices," Journal of Political Economy, Volume 96, (April 1988), 246-273.

Grossman, Sanford J. and Robert J. Shiller, "The Determinants of the Variability of Stock Market Prices." American Economic Review, 71 (May 1981), 222-27.

Hamilton, James D., "A New Approach to the Economic Analysis of Nonstationary Time Series and the Business Cycle," manuscript, University of Virginia, 1988, (forthcoming, Econometrica).

Ibbotson, Roger G. and Rex A. Sinquefield, Stocks, Bonds, Bills, and Inflation: The Past and the Future. Charlottesville, VA: Financial Analysts Research Foundation, 1982.

Lam, Pok-sang, "On Hamilton's New Approach to the Economic Analysis of Nonstationary Time Series," manuscript, The Ohio State University, 1988.

Leroy, Stephen F., "Risk Aversion and the Martingale Property of Stock Prices." International Economic Reviev 14 (June 1973), 436-46.

Lo, Andrew $W$. and Craig A. Mackinlay, "Stock Market Prices Do Not Follow Random Valks: Evidence from a Simple Specification Test," forthcoming, Review of Financial Studies.

Lucas, Robert E. Jr., "Asset Prices in an Exchange Economy," Econometrica $66,(1978), 1429-1445$.

Michener, Ronald W. "Variance Bounds in a Simple Model of Asset Pricing," Journal of Political Economy, 90 (1982), 166-75.

Neftci, Salih N., "Are Economic Time Series Asymmetric over the Business Cycle?" Journal of Political Economy 92 (April 1984), 307-328. 
Poterba, James M. and Lawrence H. Summers, " Mean Reversion in Stock Prices: Evidence and Implications," NBER Working Paper No. 2343, August 1987 .

Romer, Christina D. "World Var I and the Post-War Depression: A Reinterpretation Based on Alternative Estimates of GNP," Journal of Monetary Economics 22 (July 1985), 91-116.

- The Pre-War Business Chcle Reconsidered: New Estimates of Gross National Product, 1869-1918," Journal of Political Economy, 97 (February 1989), forthcoming.

Shiller, Robert J., "Do Stock Prices Move Too Much to be Justified by Subsequent Movements in Dividends?" American Economic Review 71 (June 1981), 421-436.

Summers, Lawrence H., "Does the Stock Market Rationally Reflect Fundamental Values?" Journal of Finance 41, 591-600.

Vest, Kenneth D. "Dividend Innovations and Stock Price Volatility," Econometrica 56 (January 1988), 37-62.

Vilson, Jack W. and Charles Jones, "A Comparison of Annual Common Stock Returns: 1871-1925 with 1926-1985," Journal of Business 60 (April 1987), 239-258. 


\section{Appendix}

In this appendix we derive the equilibrium price function ( 7 ).

Lover case letters are used to denote variables in logarithmic form (i.e., $x$ - $\log (X))$. Given the stochastic process for the exogenous forcing variable in equations (5)-(6), the problem is to find the solution to (4), which we reproduce here for convenience.

$$
P_{t}=D_{t}^{-\gamma} \sum_{k=1}^{\infty} \beta^{k} E_{t} D_{t+k}^{1+\gamma} .
$$

We proceed in two steps.

I. It is useful to write $d_{t}$ as the sum of a trend, $n_{t}$, and noise, $\varepsilon_{t}$. Tha: is,

$$
\begin{aligned}
& d_{t+1}=n_{t+1}+\varepsilon_{t} \\
& n_{t+1}=n_{t}+\alpha_{0}+\alpha_{1} s_{t}
\end{aligned}
$$

From equations $(a .2),(a .3)$, and (6) in the text, it follows that

$$
d_{t+k}=d_{t}+\left(n_{t+k}-n_{t}\right)+\sum_{j=1}^{k} \varepsilon_{t+j}, k=1,2, \ldots
$$

(a.4) can then be manipulated to obtain,

$$
\beta^{k} D_{t+k}^{1+r}=\beta^{k}\left[D_{t} N_{t}^{-1} N_{t+k} \exp \left(\sum_{j=1}^{k} \varepsilon_{t+j}\right)\right]^{1+r} .
$$


Now take expectations on both sides of (a.5) conditioned on time $t$ information. Exploit the independence and normality of the $\left[\varepsilon_{t}\right\}$ sequence to obtain,

$$
\beta^{k} E_{t} D_{t+k}^{1+Y}=\left(D_{t} N_{t}^{-1}\right)^{1+Y} \hat{\beta}^{k} E_{t} N_{t+k}^{1+Y}
$$

where $\dot{\beta} \equiv \beta, \exp \left[(1+\gamma)^{2} \sigma^{2} / 2\right]$. Now sum (a.6) to obtain,

$$
\sum_{k=1}^{\infty} \beta^{k} E_{t} D_{t+k}^{1+\gamma}=\left(D_{t} N_{t}^{-1}\right)^{1+\gamma} \sum_{k=1}^{\infty} \beta^{k} E_{t} N_{t+k}^{1+r}
$$

The problem now is to evaluate $\sum_{k=1}^{\infty} \beta^{k} E_{t} N_{t+k}^{1+\gamma}$.

II. From equation (a.2), it follows that,

$$
n_{t+k}=n_{t}+k \alpha_{0}+\alpha_{1} i_{t, k-1}+\alpha_{1} s_{t}, k=1,2, \ldots
$$

where $i_{t, k} \equiv \sum_{j=1}^{k} s_{t+j}$ is the total number of "ones" realized from $t+1$ to $t+k$, and $i_{t, 0} \equiv 0 .(a .8)$ can be manipulated to obtain,

$$
\hat{\beta}^{k} N_{t+k}^{1+\gamma}=N_{t+1}^{1+\gamma} \dot{\beta}\left(\dot { \beta } ^ { k - 1 } \operatorname { e x p } \left((1+\gamma)\left((k-1) \alpha_{0}+\alpha_{1} i_{t, k-1} 1\right) .\right.\right.
$$

Now sum (a.9) and take expectations conditioned on time $t$ information to obtain,

$$
\sum_{k=1}^{\infty} \dot{\beta}^{k} E_{t} N_{t+k}^{1+\gamma}=N_{t+1}^{1+\gamma} \dot{\beta} E_{t} \sum_{j=0}^{\infty} \dot{\beta}^{j} \exp \left[(1+\gamma)\left(\alpha_{0} j+\alpha_{1} i_{t, j}\right)\right] .
$$


To evaluate (a.10), we use a result due to Hamiltion (see his equation 3.17 ), which we paraphrase as follows:

Result 1. Let $\left\{s_{t}\right\}$ be a Markov random variable which assumes values of 0 or 1 according to the transition probabilities given by (6), and let $i_{t, k} \equiv \sum_{j=1}^{k} s_{t+j}$, where $i_{t, 0} \geqslant 0$. Then for $0<\delta<1$,

$$
\begin{aligned}
& E_{t=0}^{\infty} \sum_{j=0}^{j} \exp \left[\left(\alpha_{0} j+\alpha_{1}{ }_{t}{ }_{t, j}\right)\right]= \\
& \frac{1-f\left(s_{t}\right) \delta \exp \left(\alpha_{0}\right)}{\left.1-\delta \exp \left(\alpha_{0}\right)\left(p \exp \left(\alpha_{1}\right)+q\right)+\delta^{2} \exp \left(2 \alpha_{0}+\alpha_{1}\right)\right)(p+q-1)},
\end{aligned}
$$

where $f\left(s_{t}\right)=\left\{\begin{array}{ll}(p+q-1) \exp \left(\alpha_{1}\right) s_{t}=0 \\ p+q-1 & s_{t}=1\end{array}\right.$.

Now use Result 1 to obtain,

$$
\sum_{k=1}^{\infty} \hat{\beta}^{k} E_{t} N_{t+k}^{1+\gamma}=\frac{N_{t+1}^{1+\gamma} \dot{\beta}\left[1-f\left(s_{t}\right) \tilde{\beta}_{3}\right.}{1-\hat{\beta}\left(p \tilde{\alpha}_{1}+q\right)+\tilde{\beta}^{2} \tilde{\alpha}_{1}(p+q-1)} \text {, }
$$

where as in the text, $\tilde{\beta}=\beta \exp \left[\alpha_{0}(1+\gamma)+(1+y)^{2} \sigma^{2} / 2\right]$ and $\tilde{\alpha}_{1}=$ $\exp \left[\alpha_{1}(1+\gamma)\right]$. Notice that for given values of $\left(p, q, \alpha_{0}, \alpha_{1}, \sigma\right)$, Result 1 places an upper bound on agent's subjective discount factor, $\beta$. The value used in all of our simulations $(0.98)$ is within the admissible region. Finally, substitution of (a.12) into (a.7) and (a.1) yields, 


$$
P_{t}=\frac{\tilde{\beta} \exp \left[(1+\gamma) \alpha_{1} s_{t}\right]\left[\tilde{I}-f\left(s_{t}\right) \tilde{\beta}\right]}{1-\tilde{\beta}\left(p \tilde{\alpha}_{1}+q\right)+\tilde{\beta}^{2} \tilde{\alpha}_{1}(p+q-1)} D_{t},
$$

which is equation (7) in the text. 
Table 1 .

Maximum Likelihood Estimates and Summary Statistics of the Forcing Process

$$
\begin{gathered}
y_{t+1}=y_{t}+\alpha_{0}+\alpha_{1} s_{t}+\varepsilon_{t+1} \\
\text { Prob }\left[s_{t+1}=1 \mid s_{t}=1\right]=p \\
\text { Prob }\left[s_{t+1}=0 \mid s_{t}=1\right]=1-p \\
\text { Prob }\left[s_{t+1}=0 \mid s_{t}=0\right]=q \\
\text { Prob }\left[s_{t+1}=1 \mid s_{t}=0\right]=1-q \\
\varepsilon \text { i.i.d. } \sim N\left(0, \sigma^{2}\right)
\end{gathered}
$$

\begin{tabular}{|c|c|c|c|c|}
\hline Series & Mean & Std. Dev. & Maximum & Minimum \\
\hline $\begin{array}{l}\text { Dividends } \\
\text { GNP } \\
\text { Consumption }\end{array}$ & $\begin{array}{r}-0.0038 \\
0.0183 \\
0.0184\end{array}$ & $\begin{array}{l}0.1359 \\
0.0547 \\
0.0379\end{array}$ & $\begin{array}{l}0.4056 \\
0.1662 \\
0.0989\end{array}$ & $\begin{array}{l}-0.4673 \\
-0.2667 \\
-0.1044\end{array}$ \\
\hline
\end{tabular}

\section{Summary Statistics for Growth Rates of the Data:}

\begin{tabular}{ccccc} 
Parameter & Dividends & $\underline{\text { GNP }}$ & Consumption \\
\cline { 5 - 5 } $\mathrm{p}$ & $\begin{array}{c}0.1748 \\
(0.832)\end{array}$ & $\begin{array}{c}0.5096 \\
(2.034)\end{array}$ & $\begin{array}{c}0.5279 \\
(1.985)\end{array}$ \\
$\mathrm{q}$ & $\begin{array}{c}0.9508 \\
(40.785)\end{array}$ & $\begin{array}{c}0.9817 \\
(76.705)\end{array}$ & $\begin{array}{c}0.9761 \\
(46.525)\end{array}$ \\
$\sigma$ & 0.1050 & 0.0433 & 0.0320 \\
& $(13.682)$ & $(14.932)$ & $(12.297)$ \\
$\alpha_{0}$ & 0.0131 & 0.0157 & 0.0151 \\
& $(1.579)$ & $(5.950)$ & $(6.467)$ \\
$\alpha_{1}$ & -0.3700 & -0.1760 & -0.0926 \\
& $(-6.548)$ & $(-7.116)$ & $(-4.894)$
\end{tabular}


Table 2

A. Variance Ratios.

\section{Exogenous forcing process calibrated to}

\begin{tabular}{|c|c|c|c|c|c|c|}
\hline & \multicolumn{2}{|c|}{ Dividends } & \multicolumn{2}{|c|}{ output } & \multicolumn{2}{|c|}{ Consumption } \\
\hline$\tau$ & $\begin{array}{l}1 \\
\gamma=0\end{array}$ & $\begin{array}{l}\text { Contri- } \\
\text { bution } \\
\text { of } \gamma=-1.4\end{array}$ & $\begin{array}{l}\text { Bias } \\
\gamma=0\end{array}$ & $\begin{array}{l}\text { Contri- } \\
\text { bution } \\
\text { of } \gamma=-1.6\end{array}$ & $\begin{array}{l}\text { Bias } \\
\gamma=0\end{array}$ & $\begin{array}{l}\text { Contri- } \\
\text { bution } \\
\text { of } r=-1.7\end{array}$ \\
\hline 1 & 0.0000 & 0.0000 & 0.0000 & 0.0000 & 0.0000 & 0.0000 \\
\hline 2 & -0.0118 & $-0,1180$ & -0.0195 & -0.0460 & -0.0134 & $-0,0434$ \\
\hline 3 & -0.0301 & -0.1639 & -0.0580 & -0.0773 & -0.0382 & -0.0753 \\
\hline 4 & -0.0456 & -0.1806 & -0.0935 & -0.0906 & -0.0605 & -0.1013 \\
\hline 5 & -0.0594 & -0.1925 & -0.1211 & -0.1039 & -0.0877 & -0.1110 \\
\hline 6 & -0.0717 & -0.2062 & -0.1416 & -0.1195 & -0.1027 & -0.1237 \\
\hline 7 & -0.0866 & -0.2018 & -0.1478 & -0.1371 & -0.1298 & -0.1216 \\
\hline 8 & -0.1012 & -0.2068 & -0.1769 & -0.1229 & -0.1469 & -0.1248 \\
\hline 9 & -0.1162 & -0.2097 & -0.1916 & -0.1248 & -0.1597 & -0.1325 \\
\hline 10 & -0.1242 & -0.2091 & -0.2022 & -0.1362 & -0.1760 & -0.1287 \\
\hline
\end{tabular}

\section{B. Regression Coefficients.}

\section{Exogenous forcing process calibrated to}

\begin{tabular}{|c|c|c|c|c|c|c|}
\hline & \multicolumn{2}{|c|}{ Dividends } & \multicolumn{2}{|c|}{ Output } & \multicolumn{2}{|c|}{ Consumption } \\
\hline$\tau$ & $\begin{array}{l}\quad 1 \\
\begin{array}{l}\text { Bias } \\
\gamma=0\end{array}\end{array}$ & $\begin{array}{l}\text { Contri- } \\
\text { bution } \\
\text { of } \gamma=-1.4\end{array}$ & $\begin{array}{l}\text { Bias } \\
\gamma=0\end{array}$ & $\begin{array}{l}\text { Contri- } \\
\text { bution } \\
\text { of } \gamma=-1.6\end{array}$ & $\begin{array}{l}\text { Bias } \\
\gamma=0\end{array}$ & $\begin{array}{l}\text { Contri- } \\
\text { bution } \\
\text { of } \gamma=-1.7\end{array}$ \\
\hline 1 & -0.0156 & -0.1135 & -0.0201 & -0.0448 & -0.0120 & -0.0475 \\
\hline 2 & -0.0250 & -0.0828 & -0.0577 & -0.0580 & -0.0396 & -0.0599 \\
\hline 3 & -0.0357 & -0.0566 & -0.0703 & -0.0542 & -0.0534 & -0.0575 \\
\hline 4 & -0.0504 & -0.0438 & -0.0766 & -0.0459 & -0.0661 & -0.0496 \\
\hline 5 & -0.0634 & -0.0336 & -0.0829 & -0.0450 & -0.0778 & -0.0385 \\
\hline 6 & -0.0720 & -0.0323 & -0.0947 & -0.0401 & -0.0846 & -0.0374 \\
\hline 7 & -0.0886 & -0.0282 & -0.1041 & -0.0282 & -0.0988 & -0.0317 \\
\hline 8 & -0.1022 & -0.0204 & -0.1178 & $=0.0262$ & -0.1155 & -0.0211 \\
\hline 9 & -0.1222 & -0.0145 & -0.1234 & -0.0257 & -0.1252 & -0.0269 \\
\hline 10 & -0.1389 & -0.0171 & -0.1417 & -0.0251 & -0.1335 & -0.0296 \\
\hline
\end{tabular}

1. Median from Monte Carlo distribution generated under assumption that $\gamma=0$ less the theoretical value.

2. Difference between median of Monte Carlo distribution generated with $\gamma<0$ and the median generated with $\gamma=0$. 


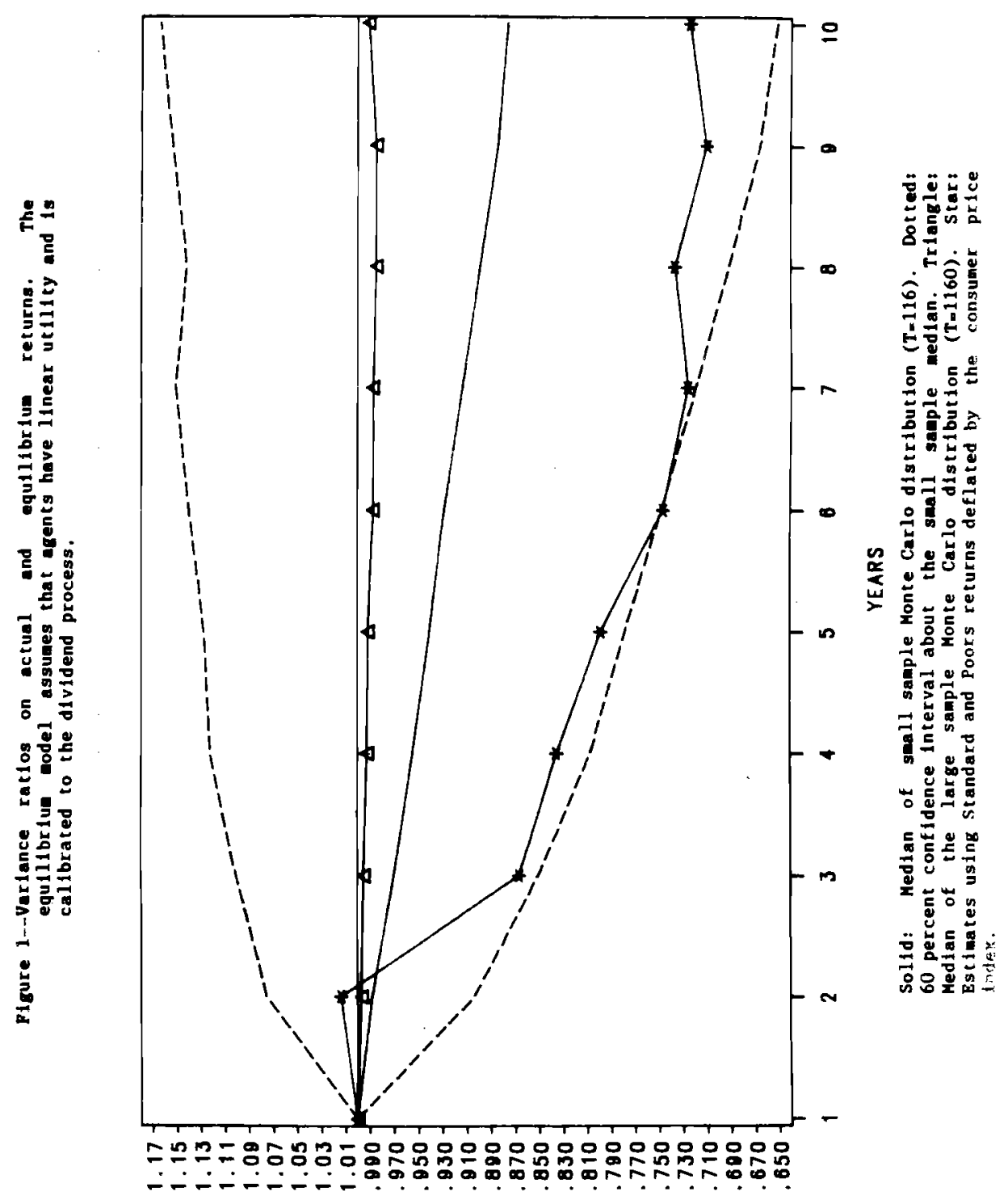




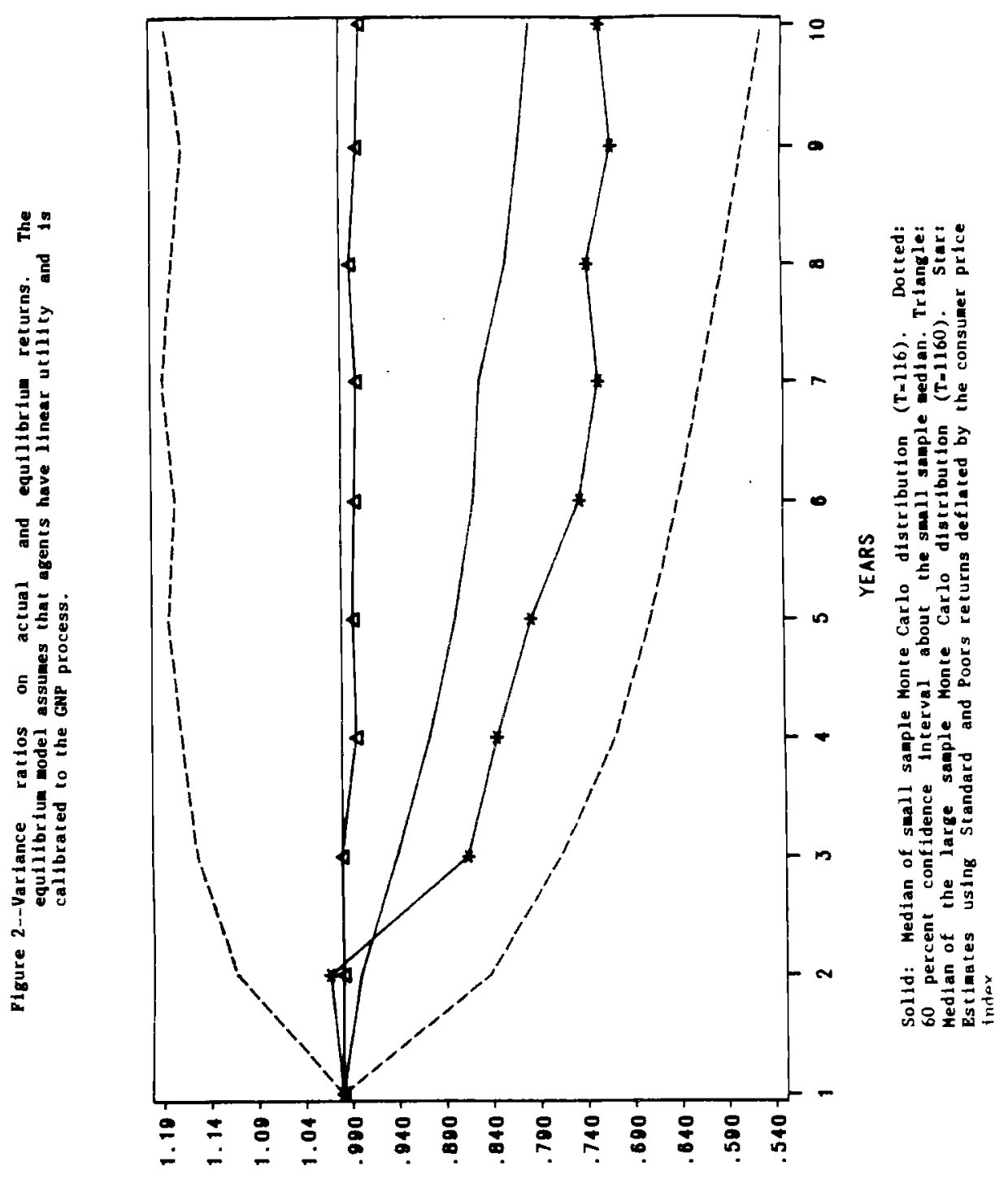




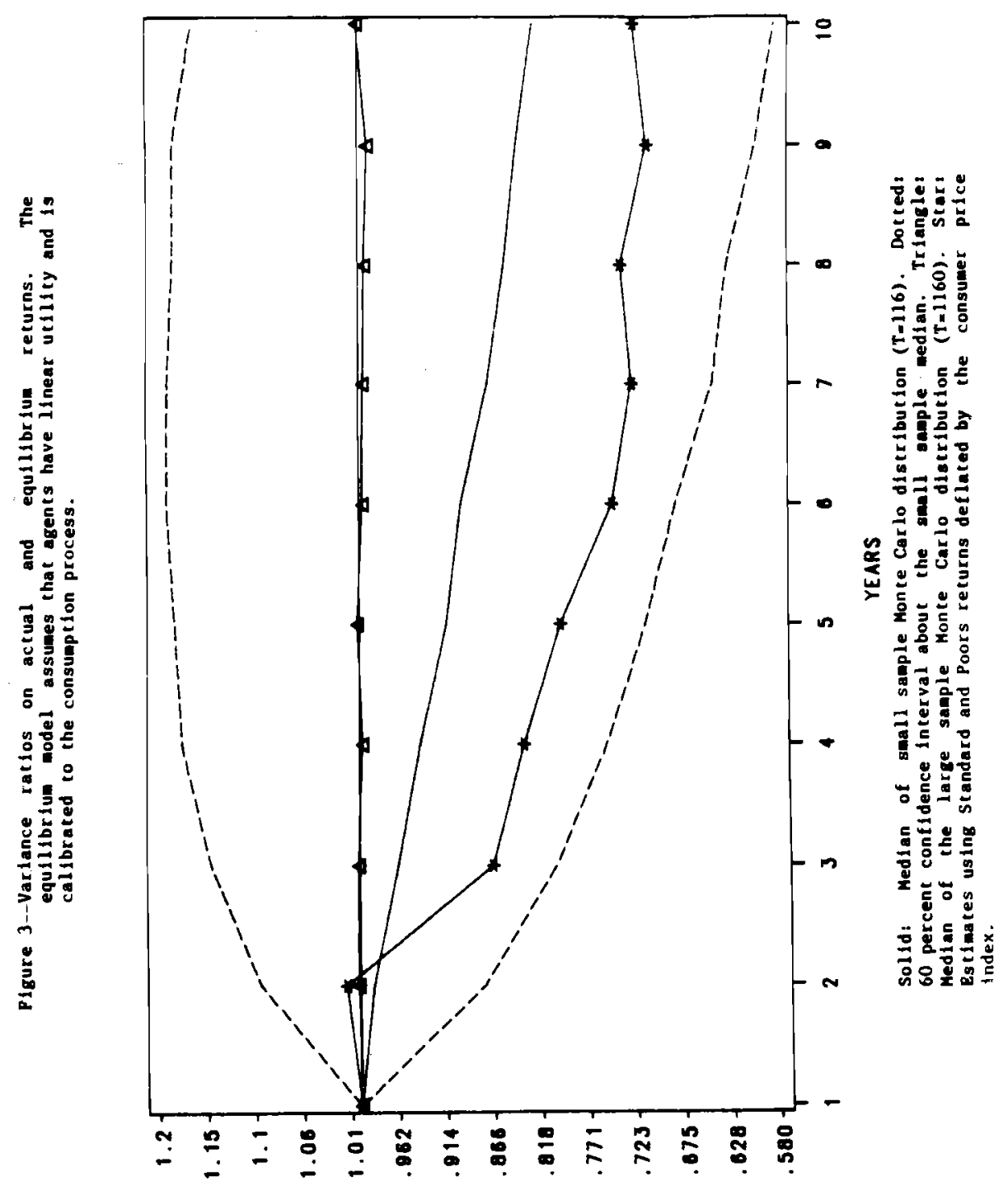




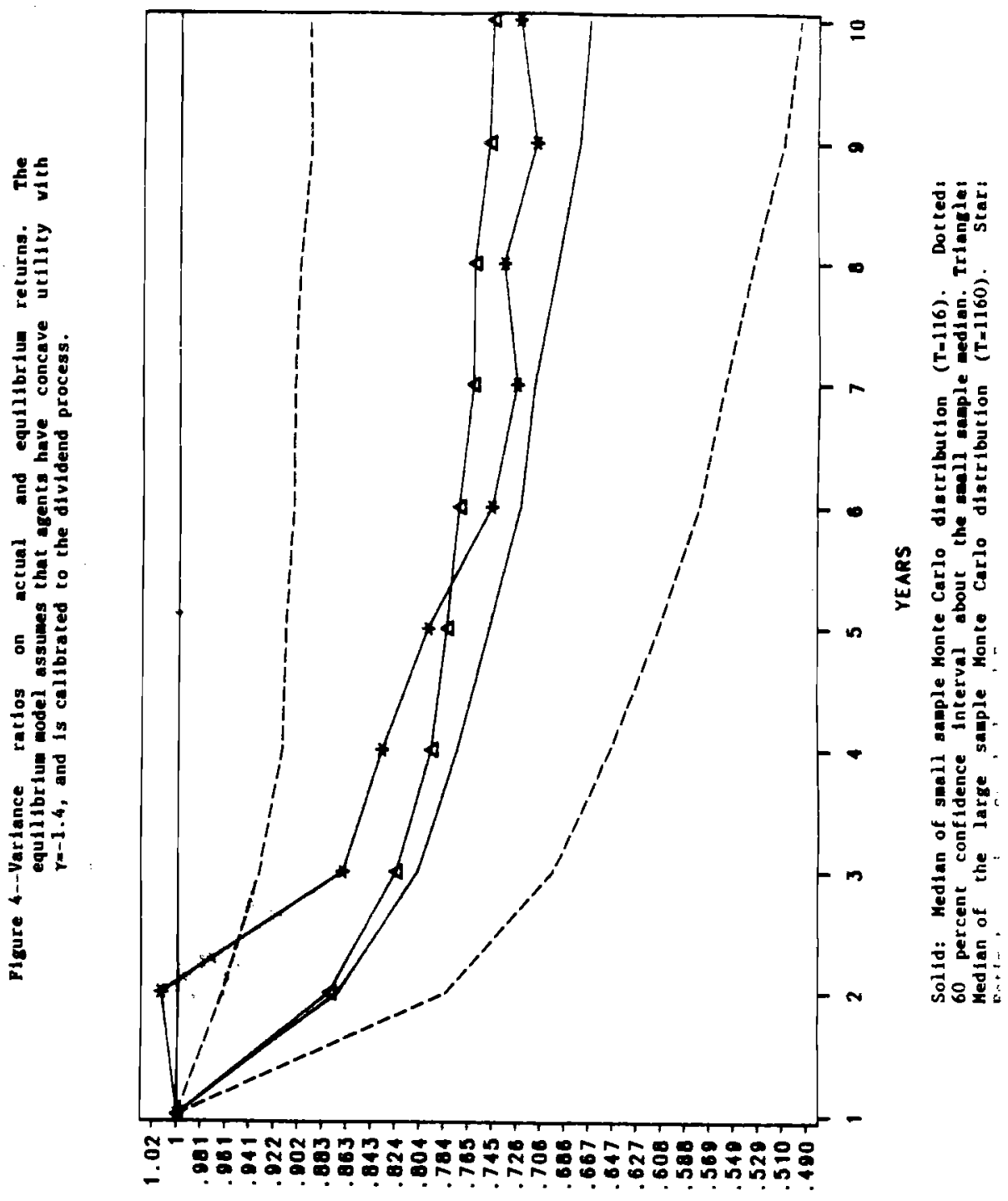




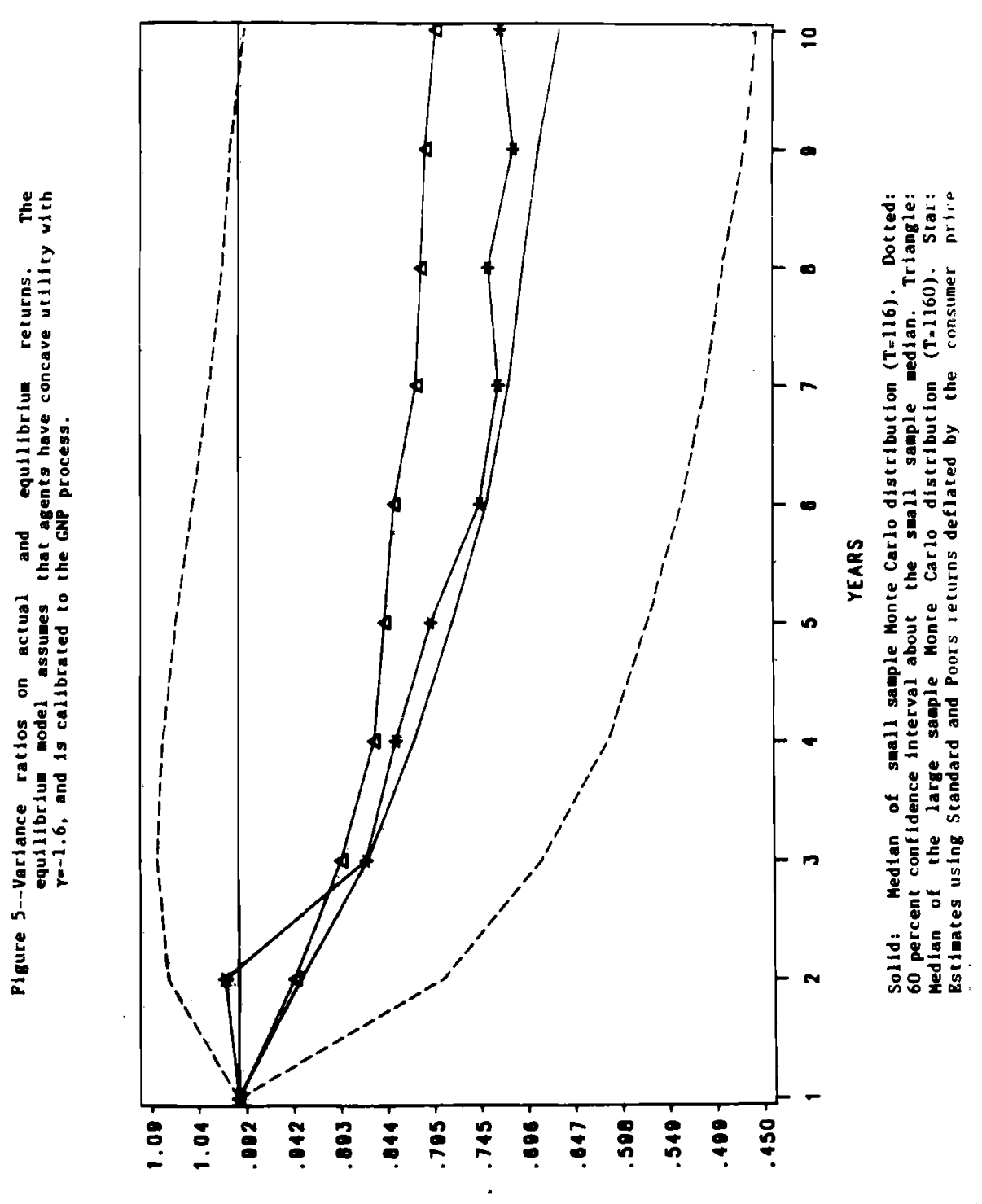




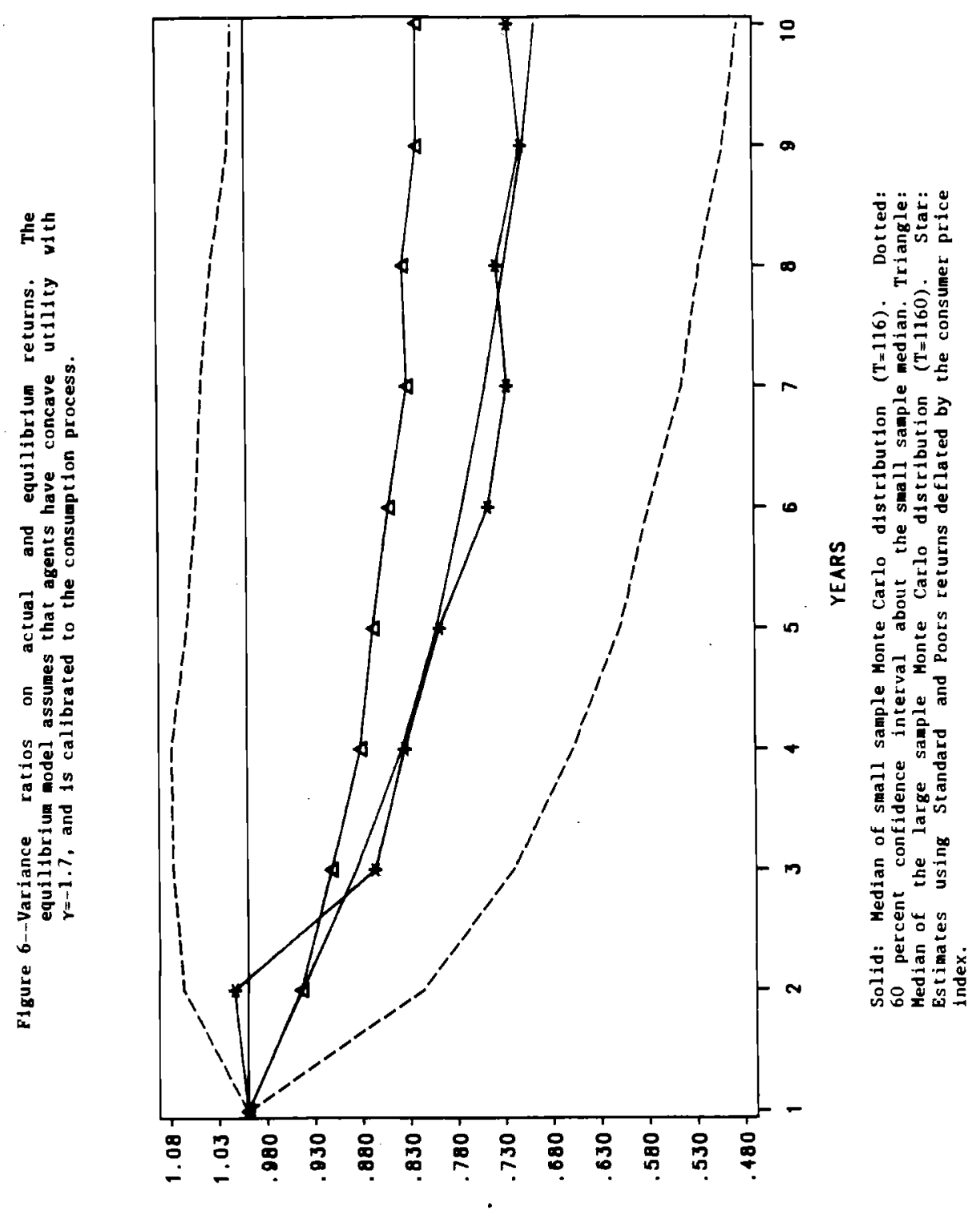



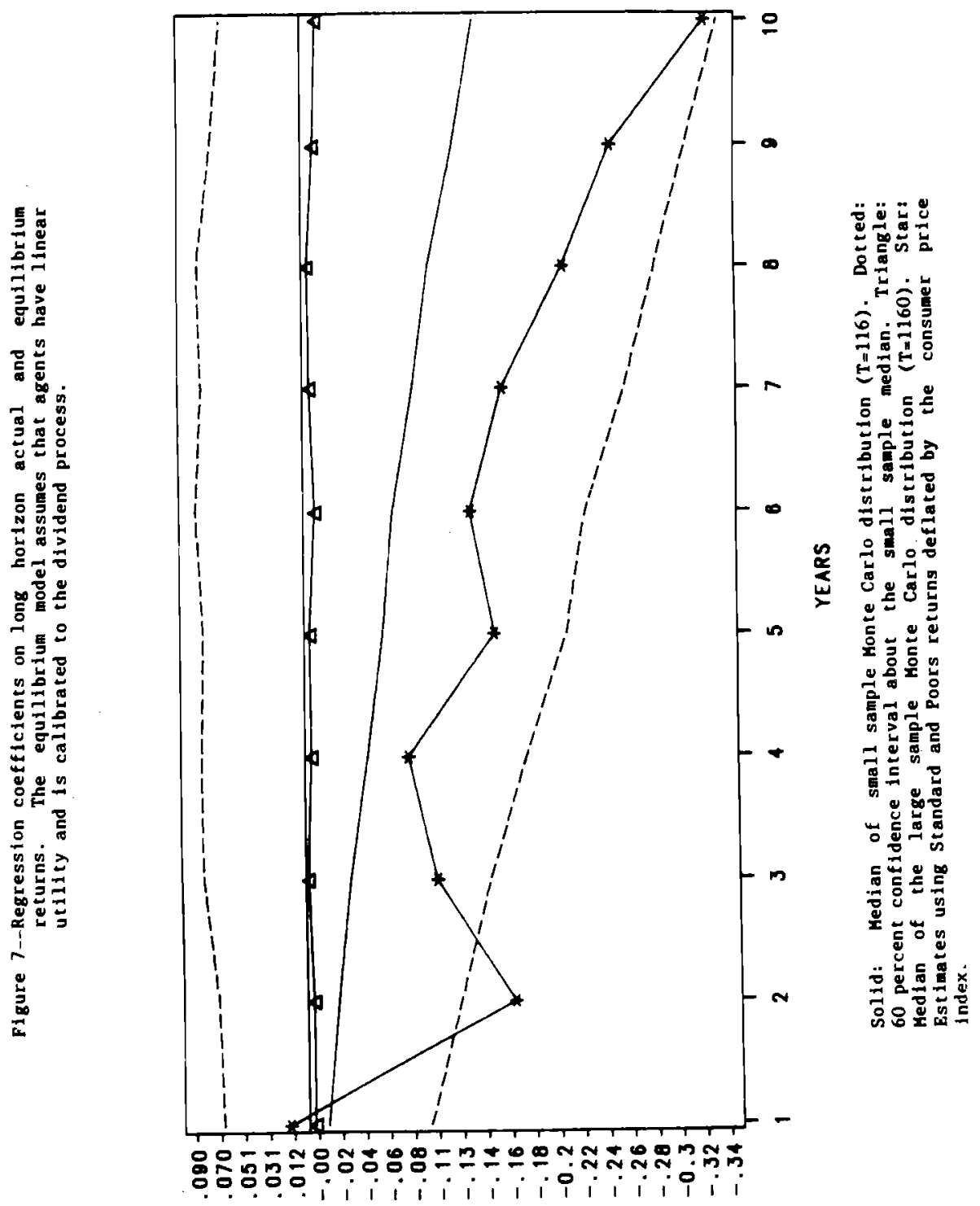


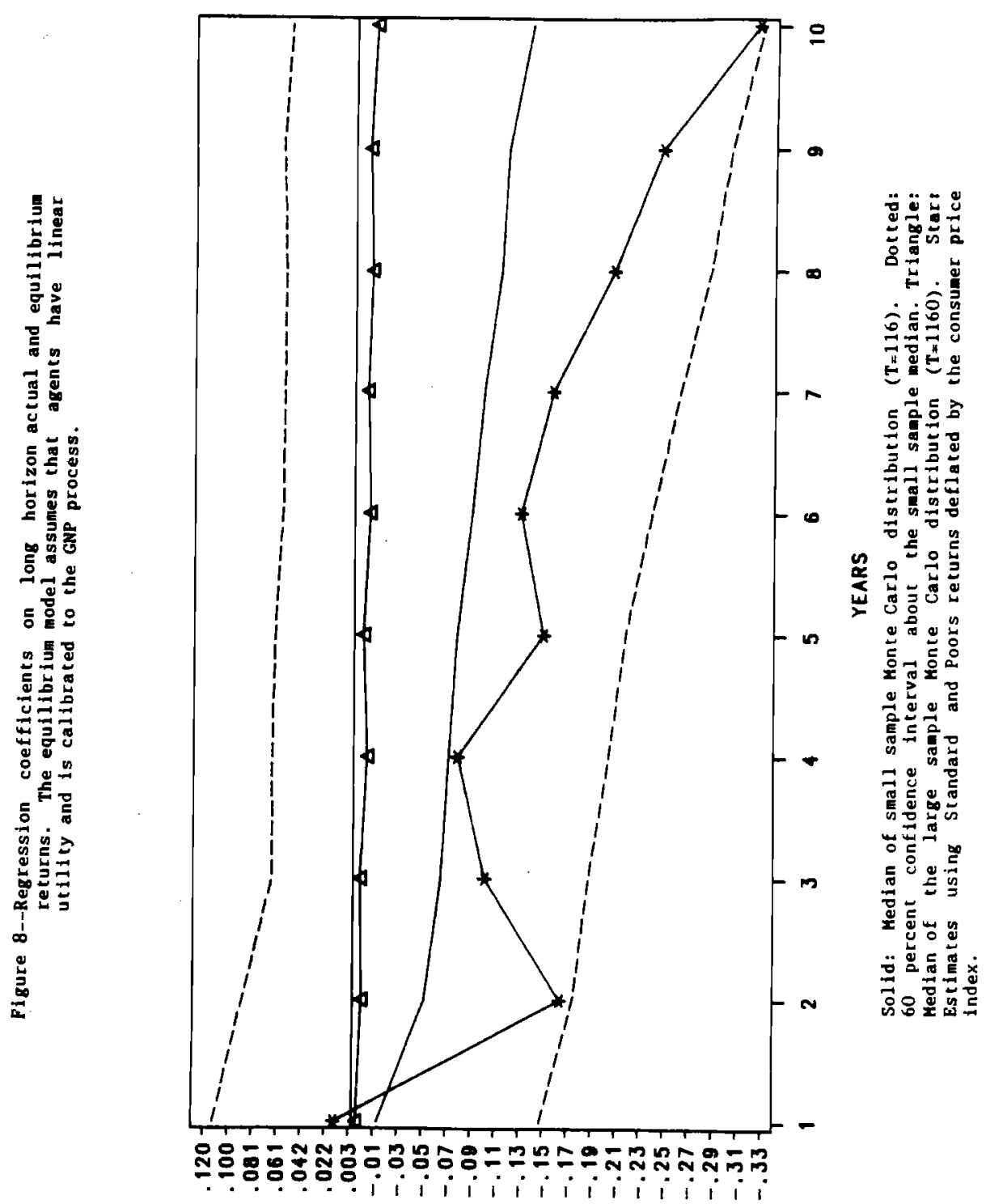



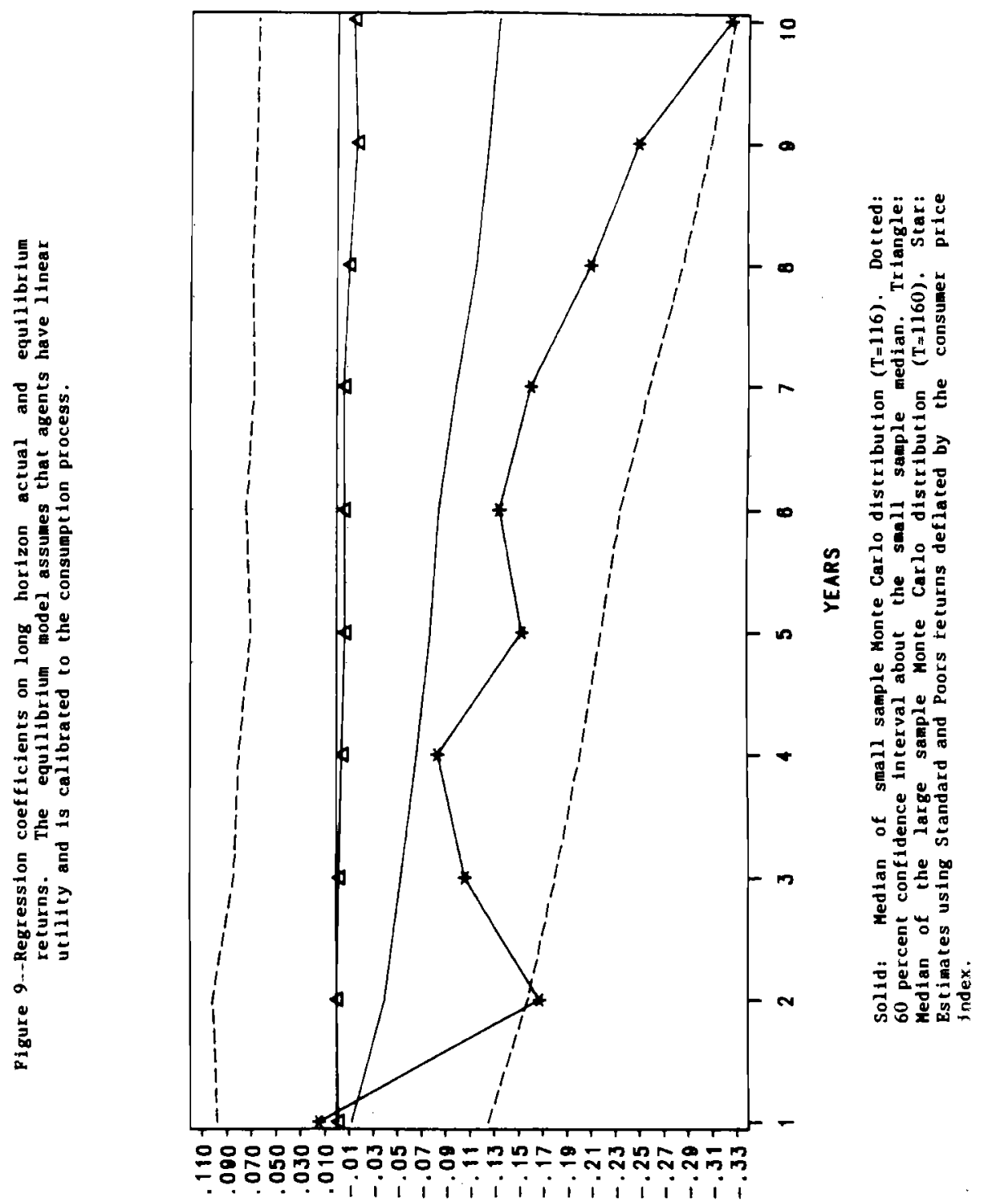

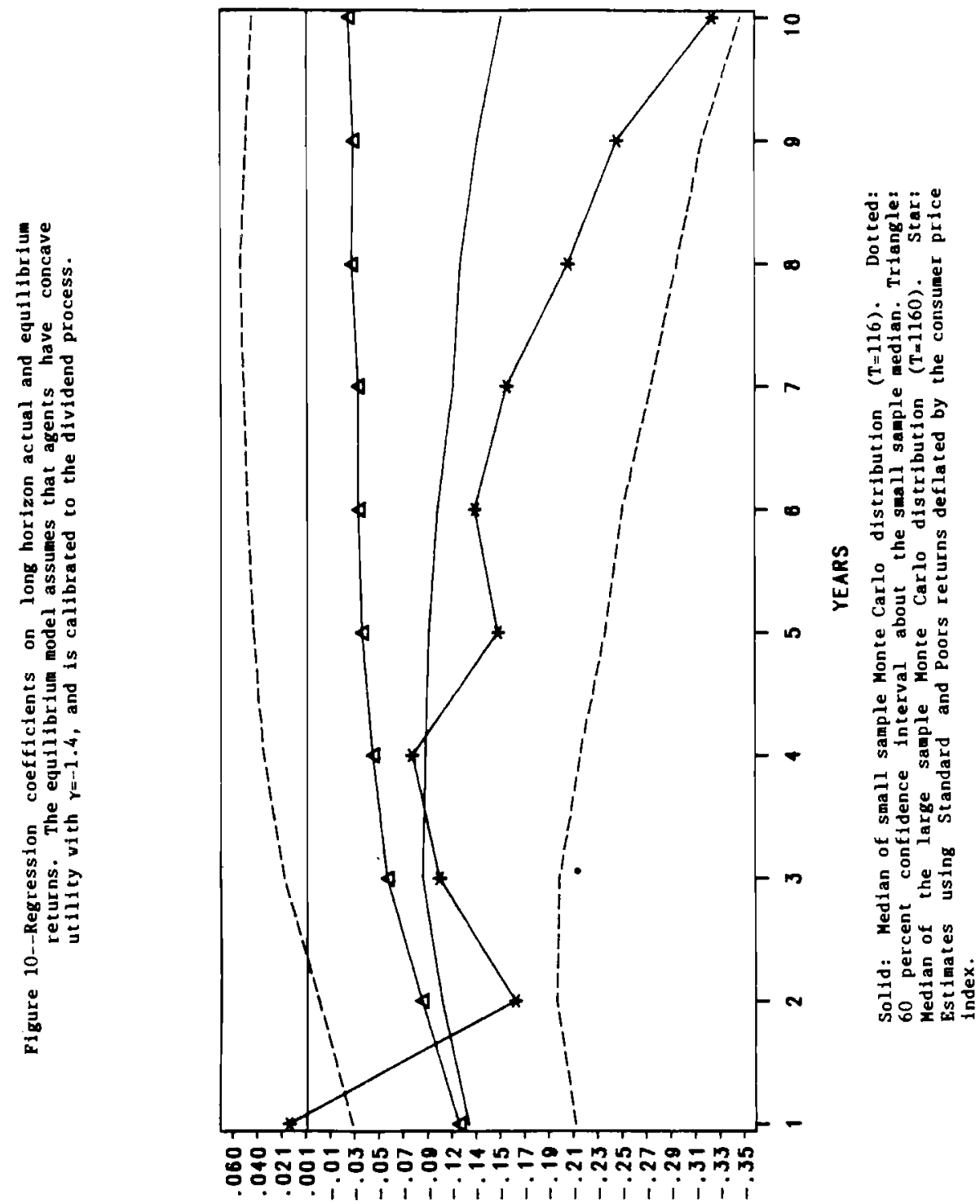


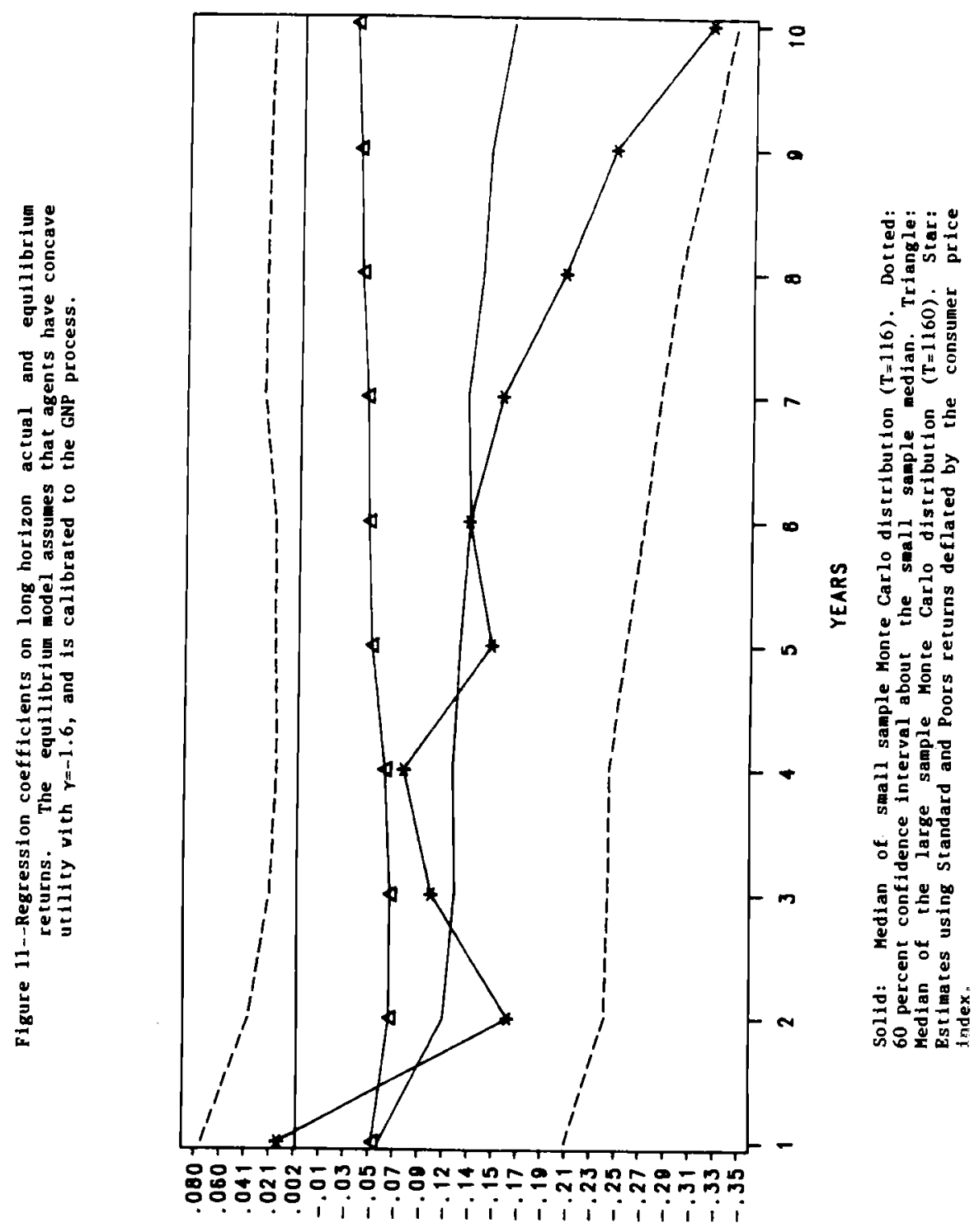



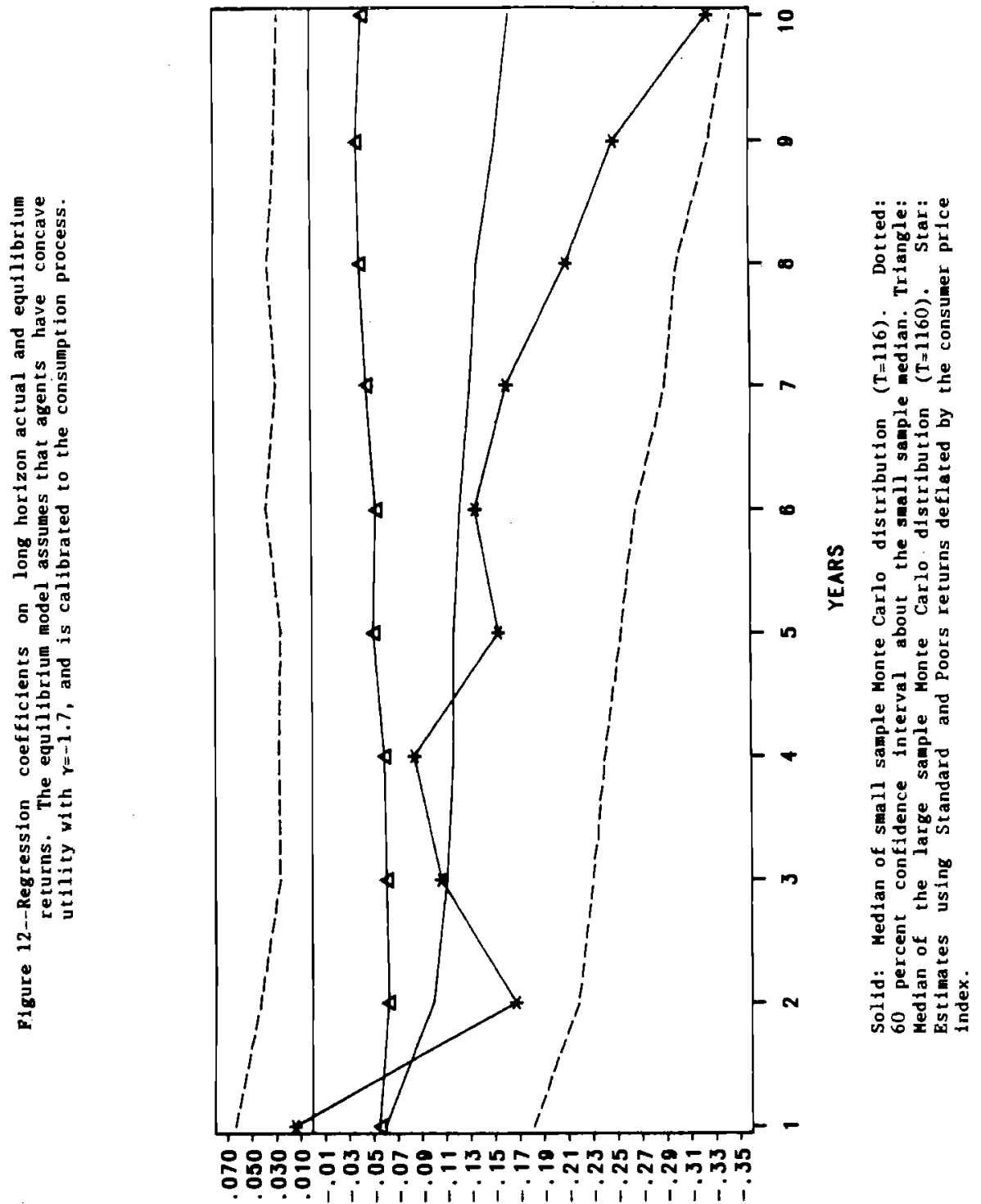